\title{
The value trade-off in Higher Education service: A qualitative intercultural approach to students' perceptions
}

\author{
Danni Li ${ }^{1} \mathbb{D}$, Martina Gallarza Granizo ${ }^{2}$ D, Teresa Fayos Gardó2 ${ }^{[D}$ \\ ${ }^{1}$ Guangzhou Maritime Institute (China) \\ ${ }^{2}$ Universidad de Valencia (Spain)
}

sue222222@163.com, martina.gallarza@uv.es, teresa.fayos@uv.es

Received July, 2015

Accepted March, 2016

\section{Abstract}

Purpose: Higher Education Institutions (HEIs) have become a highly competitive market, where consumers (i.e. students) are highly involved in their choices, and managers need to focus on competitive edges. This paper aims to understand the factors that influence international Master students' choice behaviour and fulfil student expectations of customer value in HEIs.

Design/methodology: With qualitative information (five focus groups) collected from international students (of 12 different nationalities) of several universities in Spain, UK and China, the paper investigates the formation of customer value as a trade-off between benefits and costs. This qualitative approach aims first at assessing this particular service through the concept of value through verifying both the positive and negative dimensions of educational service, and second, to comment on the intercultural aspects of this dual approach to higher education consumption.

Findings: The results show different levels of benefits: the functional value generally comes from infrastructures and good teachers that offer abundant practical experiences. The benefits from quality education also derived from teamwork with the colleagues who possess equal academic strength. Social benefits come from experiences outside the academic environment, 
working with people from different cultural backgrounds who have different perspectives. Emotional rewards come from University reputation and relationships with instructors. Costs of time and effort are differently seen across programs and vary widely upon nationalities and cultural backgrounds.

Practical implications: Since the competitive environments of HEIS are fast becoming more and more complex changing rapidly and dynamically, attention must be paid to International students spreading positive or negative word-of-mouth out of their experience. Different values of customers in different countries suggest that the strategy used by the corporation in a certain country, may not be apply to another.

Social implications: The results of the study allow the industry to see the future prospects of the meat sector and make the necessary changes. The results lead to improved transparency and responsible behaviour.

Originality/value: Within the wide trend of research on students' choice, this work has focused on International Master Students, a public with relatively limited number of studies. The contribution lays on a value-based approach as a trade-off focusing, as a step forward from the traditional sociodemographic approaches, on behavioural variables (functional, social and emotional values) and considering not just price but also non-monetary costs.

Keywords: Higher Education Service, Focus groups, Value dimensions, Perceived Value, Benefits, Costs, Intercultural comparisons

Jel Codes: I23; M31

\section{Introduction}

Higher Education Institutions (HEIs) have become in the last decade a highly competitive market, where consumers (i.e. students) are highly involved in their choices, and managers need to focus on competitive edges. Positive image, service quality, students' satisfaction, consumer value and word of mouth communication are the key strategic variables in maintaining such a competitive position (Ledden, Kalafatis \& Samouel 2007; Marín-García, Martínez-Gómez \& Giraldo-O’Meara, 2014), resulting in long-term benefits arising from students' loyalty (Arambewela, Hall \& Zuhair, 2005). 
Obtaining market attractiveness for HEIs involves understanding significant pecuniary and nonpecuniary gains from full-fee paying students and how this will result in a more competitive environment (Arambewela et al., 2005) and thus will improve their market position. This process requires educational institutions to carefully understand how value perceptions arise as both positive and negative factors that lead to customer satisfaction, which in turns result in higher levels of loyalty and positive word of mouth, i.e. to fully understand the value-satisfaction-loyalty chain (Boksberger \& Melsen, 2011; Gallarza, Gil-Saura \& Holbrook, 2011).

This paper aims to understand the factors that fulfil students' perception toward quality and other value dimensions, in opposition to the constraints found when engaging in one better than another service of higher education. In this respect, by adopting a value-based approach as a trade-off, the main objective of this work is to explore students' choice behaviour in the HEIs market. According to previous literature (e.g. Bamber, 2014; Deshields, Kara \& Kaynak, 2005; Ledden et al., 2007; Moogan, 2001; Watt, Angelis \& Chapman, 2012) the value trade-off that considers both benefits and sacrifices when assessing offerings can be applied to the experience of consuming HE service.

There is substantial research on higher education choice (e.g. Angulo, Pergelova \& Rialp, 2010; Bonnema \& van der Weldt, 2008; Fombona, Rodríguez \& Sevillano, 2013; Reay, Davies, David \& Ball, 2001) and consumption as a service experience (e.g. Arambewela et al., 2005; Bitew, 2016; Ledden et al. 2007; Marín-García, et al., 2014); however, the trend has focused particularly on the socio-economic characteristics explaining this behaviour, and more rarely on psychographics and behavioural factors. Furthermore, regarding costs and sacrifices as negative drivers for students' choice, previous works have concentrated more on prices (Hemsley-Brown \& Oplatka, 2015) than in any other costs (such as non-monetary ones such as time and effort). Accordingly, we consider there is considerable space for new research focusing on more behavioural variables such as the dimensionality of value, being functional, social and emotional in nature, and with consideration of both monetary and non-monetary costs.

The precise level in higher education chosen to achieve our research aim is the postgraduate experience. In a recent meta-analysis of previous works on University choice, Hemsley-Brown and Oplatka (2015, pp. 268) signalled that "the relatively limited number of studies regarding international students choice of university outside their home countries is surprising". Taking into consideration the global scope of the University Education market nowadays, this gap in previous works has been a clear motivation for undertaking the present work with international Master students, more mature and fully aware of their choices. 
The methodology performed is a qualitative approach with five focus groups in three different countries (Spain, China and the UK) and with students from 12 different nationalities to fully capture the peculiarities of the students' behaviours, and explore consumer behaviours in higher education market regarding their cultural differences. Through collective discussions, in a moderated conversation, focus groups can deepen insights through individual contributions. Besides, interaction between individuals allow for livelier and less intimidating environment, enabling collaboration, which becomes a greater way for thought generation and development (Lehmann, Mcalister \& Staelin, 2011; Patton, 2002), which is considered as a valuable approach taking in consideration the variety of motivations and complexity of drivers in education choices (Bamber, 2014; Bitew, 2016)

Indeed, we wish to fully explore the consumer behaviour of international Master students, as consumers in the particular market of choosing and consuming the higher education service. Meanwhile, this information will allow us to better understand the significance of marketing HEIs in a global and competitive environment, as our work wishes to provide a research basis to scholars and marketing practitioners for primary investigation and allocation of higher education resources in the global market of inconstant changes. In accordance, the paper seeks to explore via qualitative techniques the possible variances in the perceptions among students from different countries and the cultural impact on the students' decision-making process. In this sense, we wish to follow recent works in HE literature interested in the effects of culture on students' choice decision (Aydin, 2012; Bitew, 2016; Lee, Lee, Makara, Fissman \& Hong, 2015; Verghese \& Kamalanabhan, 2015).

Specifically, the paper is organized as followed: first, a literature review on HEIs research in the perspective of consumer behaviour will be presented; second, the research questions built on the dimensions of value will be provided; third, a qualitative research is proposed in order to gather information via focus groups about the process of assessing value dimensions of higher education from the Master student. Finally, conclusions of the study will provide guidelines for researchers on HE service as well as managerial implications for Universities that have to face a more sophisticated consumer and a higher level of competition. 


\section{Literature review}

\subsection{Higher Education Service and Higher Education management}

Education can be understood as a paradigmatic service: Lovelock (1983), in his seminal taxonomy of the nature of services, considers education as a service that provides "intangible actions directed at people's minds", showing thus how education entails always the provision of value from person-toperson. It thus supports the legitimacy of education as a service domain and establishes an appropriate context for the study of value (Ledden et al., 2007), which is understood as the core of any exchange (Holbrook, 1999).

The conceptualization of service (its nature and its characteristics) has been used throughout the evolution of research on education, to understand every new departure in Higher Education. However, the consideration of students as consumers has not always being seen as beneficial for HEIs (Eagle \& Brennan, 2007). As Mark (2013, pp. 2) stated "Although there is evidence that postsecondary students benefit from being treated like customers, the progress toward a universal adoption of a studentcustomer paradigm has been slow".In fact, the education service has always offered valuable outcomes for marketing and consumer behaviour researchers (Lee et al., 2015), but given the changes in the rationales. environments, providers and delivery methods of the Higher Education, it is important to constantly revisit the definition and ensure that the meaning of Higher Education service reflects current changes and challenges of modern context.

In Moogan (2001) Prospective Students' Decision-making Model, the authors list a series of stages that will be followed by the customers who seek for the Higher Education services. At the phase of problem recognition, there exists a gap between the assumed state and the actual situation. While the former indicates the state where customers would prefer to be in, the latter refers to the present situation that the customers picture themselves. It is therefore the customers' decision whether to solve the disparity or not as a matter of fact, the larger the gap between the two states, the more motivated the customers will be, which result in higher likelihood the customer will act. However, In the case of a student, he/she would consider whether taking the education will be worthwhile or beneficial for them (Eagle \& Brennan, 2007; Mark, 2013). In other words, this would be a studying opportunity to solve their existing problems, for instance, to enhance their professional skills, social abilities or employment rate in the labour market. However, the idiosyncrasy of education consumption may sometimes prorogue a "potential misalignment of perceived want and need along the value chain" (Watt et al., 
2012, pp. 699) that results in a continuous adaptation of the design of the educational service, especially for Master students, which needs are more mature and determined.

For a more comprehensive understanding of the particular behaviour of Educational Services consumption, the meta-analysis made by Hemsley-Brown and Oplatka (2015) on previous research on educational choices and behaviours, allows to conclude that, there are two main groups of factors explaining Higher Education choice:

- the Institutional Factors, including Outcomes and Benefits, Institutional Characteristics and Perceived Image; and

- the interaction between the student and the institution, which contains issues such as Geography (proximity to home), Information Sources and Price Sensitivity.

A combination of all these factors is relevant for a comprehensive approach to this behaviour, although the idiocrasy of the consumption of education is always contextual and varied.

Nowadays, the stage for competition for HEIs is full of new challenges and opportunities where no single homogenous market exists (Bonnema \& van Der Weldt, 2008). As stated by Watt et al. (2012, pp. 699) "universities face an increasingly complex list of challenges, ranging from cost pressures, increased levels of demographic and cultural diversity to significant competitive threats coming from both emerging economies and private universities". In accordance, forcing by an increasingly competitive market, HEIs have a need to incorporate a better orientation to the market, seeking to obtain competitive advantages over its competitors, as well as the construction of a positive image close to its target segment (Verghese \& Kamalanabhan, 2015). In this way, it becomes fundamental to analyse and study student's satisfaction and perceived value in Higher Education, as HEIs could greatly benefit from being able to establish long term relationship with students. 


\subsection{Perceived Value: Dimensions}

The value concept has been qualified as an "amorphous concept" (Zeithaml \& Bitner, 1996, pp. 33), "multifaceted and complex" (Gallarza et al., 2011, pp. 183), and offering a "nebulous differentiation" regarding related concepts such as satisfaction and quality (Boksberger \& Melsen, 2011, pp. 230). Consequently, any review of this notion recalls "the often cited ambiguity of the value concept" (Gummerus, 2013, pp. 19).

As a matter of fact, the term value is extremely abstract to be comprehended. Nevertheless, it is also very flexible and applied to both consumer behaviour and marketing strategy (Holbrook, 1999; Gallarza et al., 2011; Leroi-Werelds Streukens, Brady \& Swinnen, 2014). In one hand, it has different meanings not only for consumers (Zeithaml, 1988) but also among researchers (Lai, 1995) and even for practitioners (Woodruff \& Gardial, 1996). On the other hand, although some differences between customer and consumer have been signalled (Lai, 1995; Jensen, 1996), from a consumer research approach, the terms "perceived value" and "consumer value", should be understood as synonymous.

There are different reasons for the usefulness of the consumer value concept. First one corresponds to the fact that epistemologically, it has evolved from the development of two pivotal dimensions of consumer behaviour: the economic dimension (i.e. perceived prices through transaction value) and the psychological dimension (emotional and cognitive elements). In addition, regarding its relationships with other constructs, theoretical proposals on value have taken discussion to a higher order, in which "value becomes a superordinate concept subsuming quality" (Oliver, 1999, pp.58), or where there is a certain superiority of value on satisfaction (Lovelock, 1996; Gallarza et al., 2011; Leroi-Werelds et al., 2014; Sweeney, Soutar \& Johnson, 1999; Woodruff, 1997).

A second quality of the value notion praised by researchers is that the value construct helps explaining different areas of consumer behaviour: product choice (e.g. Zeithaml, 1988), purchase intention (e.g. Dodds \& Monroe, 1985) and repeating purchase (e.g. Nilson, 1992). And more recently, it has also been praised as a key notion for understanding the service-dominant logic (Vargo \& Lusch, 2012) with key underpinnings in the so-called processes of value co-creation (e.g. Grönroos \& Voima, 2013; Gummerus, 2013).

Thirdly, value is inextricably linked to customer loyalty both in academic research (e.g. Parasuraman \& Grewal, 2000) and in marketing management (e.g. Bolton, Kannan \& Bramlett, 2000), and more precisely in the research of Higher Education (e.g. Ledden et al., 2007). 
Within the wide number of value conceptualizations, the early conceptual proposal made by Zeithaml (1988, pp. 4): "the overall assessment of the utility of a product based on the perceptions of what is received and what is given", is the most universally accepted definition of perceived value. In this conceptualization, value is the trade-off of benefits and sacrifices: sacrifices include both monetary costs in terms of the actual expenses and non-monetary sacrifices such as time and efforts consumed. Thus, value reveals the positive side by what is gained and the negative part of what is given up in effect. In this sense, the equation of value appears in the balancing of receipts and sacrifices.

In an opposite sense, relevant authors such as Holbrook (1999) do not consider the trade-off approach. Within an axiological perspective, Holbrook has shown a study of consistency in the topic of value, where the value in the consumption offers a broader view of consumer behaviours that could take off from the more grounded microeconomic approaches (Holbrook \& Hirschman, 1982). Holbrook's has shaped a formal typology of value perception, which proposes that consumer value as an "interactive relativistic preference experience". It also embraces eight separate categories of consumer value (efficiency, excellence (quality), play, aesthetics, esteem, status, ethics and spirituality), based on a threedimensional paradigm: extrinsic vs. intrinsic (affective vs. cognitive), active vs. reactive and finally selforiented or other-oriented when a social dimension of the act of consuming is adopted.

In one or another approach, value perceived by individuals has a direct impact when they evaluate the performance of the product or service. With certain expectations and criteria before the consumption process, it leads to the level of satisfaction from the customers. Culture in this case plays a critical role in the understanding of the value system of varied cultural cohorts of students, in regard to the marketing implication for HEIs (Arambewela et al., 2005). International students should be differentiated since the markets where they come from are embraced with distinctive cultural elements, which in turn derive different needs to satisfy. Under such circumstance, the domains underlay perceived value dimensions, containing diverse factors such as warm relationship, security, excitements, equality, inner harmony (spirituality), and comfortability. The enhancement of study experience would require the focus on traditional values shared by the groups of students, and the facilitation of good social interaction and communication, where both emotional and rational factors are at a play (Angulo et al., 2010). 


\section{Objectives and Research Questions}

In line with (Ledden et al., 2007), we want to investigate the multidimensionality of the experience of being a consumer of $\mathrm{HE}$ services, but focusing on international Master students, which as aforementioned is less common in previous literature. And this is meant to be done in a value-based approach, i.e. through the concept of value, known as a trade-off between benefits and costs (Zeithaml, 1988). According to our literature review, the value dimensions to be explored can be the ones from Holbrook (1999)'s typology, which contains dimensions such as functional, social and emotional. As in other works applying also this typology (e.g. Leroi-Werelds et al., 2014) the altruistic dimension (spirituality and ethics) are not considered, in our case due to their difficulty to be applied in HE contexts. However, Holbrook's proposal doesn't contain negative dimensions of value (Holbrook, 1999). As aforementioned, Zeithaml (1988)'s value perception, which is in relation to the part of the trade-off, involves both of the get and give components. As a result, alongside the functional, emotional and social dimensions of value, two factors of sacrifice (Zeithaml, 1988) are sought to be explored in the proposed research: monetary (price) and non-monetary (time and efforts).

Accordingly, the research questions for the present study will be:

- RQ1. To explore which aspects can be considered as benefits of consuming a Higher Education service

- RQ2. To explore which aspects can be considered as sacrifices of consuming a Higher Education service

- RQ3. To explore the evaluation process undertaken by students when valuing positive aspects of the experience of being a consumer of Higher Education

- RQ4. To explore the evaluation process undertaken by students when valuing negative aspects of the experience of being a consumer of Higher Education 


\section{Methodology}

With such research questions, explorative in nature, we adopted a qualitative approach, as suggested for these type of situations when the appraisal is not confirmatory (Lehmann et al., 2011) and when the behaviour to be investigated might vary across cultures (Lee et al., 2015).

More precisely, among the many possible qualitative techniques the method of focus group was chosen as this particular technique is efficient and practical (Kress \& Shoffner, 2007). Meanwhile, focus groups are a particularly useful tool for engaging culturally and linguistically diverse populations (Halcomb, Gholizadeh, Digiacomo, Phillips \& Davidson, 2007). Although the technique is old and endemic to the development of many social sciences (Jensen, Christy, Gettings \& Lareau, 2013; Levy, 2006), in the last decade it has moved from peripheral to center stage of qualitative research mainly for its effectiveness in terms of time and resources required (Jowett \& O'Toole, 2006). Furthermore, its convenience for intercultural settings such as the purpose of our research is also noticeable, as "focus groups .... are particularly useful tool for engaging culturally and linguistically diverse populations" (Halcomb et al., 2007, pp.100).

Regarding the field of education, qualitative research has been praised for its convenience for researching different steps in the consumption process (e.g. Winlow, Simm, Marvell \& Schaaf, 2013). Furthermore, new trends and challenges such as cultural issues and internationalization in education can be further explored through qualitative approaches (e.g. Aydin, 2012; Bamber, 2014). In this sense, we follow Hemsley-Brown and Oplatka (2015)'s work, which highlights the convenience of such qualitative approach for a better understanding of the idiosyncrasy of the educational experience.

.The sampling process corresponded to the purposeful choice of the authors based on their ability to gather valuable qualitative information from students, in this sense, "participants (were) chosen on the basis of their shared experience in relation to the research topic" (Winlow et al., 2013, pp. 295). In an educational context, this sampling procedure has been praised as positive. As Breen (2006, pp. 466) has stated, "if the focus groups are designed to investigate students' learning experiences, they should consist of participants who have been exposed to similar experiences." Accordingly, Spain, UK and China were the three countries selected as a "non-probability judgement sample" (Malhotra, 2010, pp. 379), as in this final sample researchers could benefit from interesting underpinnings for the aim pursued, such as the long tradition of HEIs in the UK, the growing presence of China in the HE arena (both in sending and receiving international students), and the interest of Spain as a choice for international students, mostly Erasmus. 
Following recommendations from previous authors on the use of focus groups (Halcomb et al., 2007; Jensen et al., 2013), we conducted five focus groups with four or five participants in each: although it is recommended to have between six and 12 participants in each group (Jensen et al., 2013; Ritchie, Lewis \& Elam, 2003), we considered that the characteristics of the phenomenon under investigation (in our case, a complex experience of consumption) define the number of groups and participants (Halcomb et al., 2007). The participants were therefore chosen based on the ideal characteristics (status: current Master students; international exchange programs; communication ability: fluency of English language) of the possible respondents and the aforementioned interests of the researchers.

\begin{tabular}{|c|c|c|c|c|}
\hline $\begin{array}{c}\text { Focus } \\
\text { Group }\end{array}$ & University & $\begin{array}{c}\text { Country where } \\
\text { FC took place }\end{array}$ & Student countries or of origin & $\begin{array}{c}\text { Number of } \\
\text { students in } \\
\text { focus group }\end{array}$ \\
\hline FGA & $\begin{array}{c}\text { Tourism Master Students } \\
\text { Polytechnic University of Valencia } \\
\text { (UPV) }\end{array}$ & Spain & $\begin{array}{c}\text { Peru } \\
\text { Mexico } \\
\text { Spain } \\
\text { Brazil } \\
\text { China }\end{array}$ & 5 \\
\hline FGB & $\begin{array}{c}\text { International MBA students from } \\
\text { University of Valencia (UV) }\end{array}$ & Spain & $\begin{array}{c}\text { Germany } \\
\text { USA (3) } \\
\text { Austria }\end{array}$ & 5 \\
\hline FGC & $\begin{array}{c}\text { Students from Master in Work, } \\
\text { Organizational, and Personnel } \\
\text { Psychology at University of Valencia } \\
\text { (UV) }\end{array}$ & Spain & $\begin{array}{c}\text { France } \\
\text { Sweden (2) } \\
\text { Germany }\end{array}$ & 4 \\
\hline FGD & $\begin{array}{c}\text { Students from several UK } \\
\text { Universities }\end{array}$ & UK & $\begin{array}{c}\text { China (2) } \\
\text { UK (2) } \\
\text { Ireland }\end{array}$ & 5 \\
\hline FGE & $\begin{array}{c}\text { Guangdong University of Foreign } \\
\text { Studies (GUFS) }\end{array}$ & China & $\begin{array}{c}\text { Shantou (Canton) } \\
\text { Jieyang (Canton) }\end{array}$ & 5 \\
\hline
\end{tabular}

Table 1. Summary of the composition of the focus groups

The 23 Master students who took part in the focus groups were 10 females and 13 males among the ages from later 20 s to early 30 s. As aforementioned, they studied in universities of three different countries (Spain, UK and China), where they have been studying their Master courses for over one year. In accordance with guidelines for selecting participants in focus groups (Finch \& Lewis, 2003; Catterall \& Maclaran, 2006) we seek for a good balance between heterogeneity in demographic and cultural profiles, but homogeneity in their behaviour as (education) consumers. Accordingly, except in one case (the UK), students in each focus group were students from the same University (one in China and two in Spain, as stated in Table 1). 
The main objective of the focus groups wasto understand students' perceived values towards the influence of positive drivers for their election (image, reputation, quality...) as well as negative factors (the monetary expense and non-monetary efforts) in the perceptions of different dimensions of value.

The specific content of the discussion related to:

- the typology of values from Holbrook (1999) which contains the functional, social and emotional values, as well as,

- two negative factors of sacrifice in relation to the trade-off (Zeithaml, 1988), in terms of the monetary costs (price) and non-monetary costs (time and efforts).

Accordingly, the specific elements that a student seeks in a Master degree were inquired. In this sense, and in accordance with literature on conduction of focus groups (Catterall \& Maclaran, 2006; Winlow et al., 2013), spontaneous interaction was encouraged and there were no written answers to fill in by participants, but the moderator followed a guide with the following questions

- A)"was the image of the University animportantfactor for your choice?"

- B) "How the social / functional / emotional aspects of your experiencematter?"

- C)“How the expenses and non-monetary costs worry you as a student?"

- D) "Is there any extra sacrifices that you have done?"

- E) “Are there any unexpected reward or benefit that you've found in your experience?”

Furthermore, the subject about the trade-off between benefits and costs when the prospective students choose a Master course was asked, which referred the students' views in their comparison with the gains and sacrifices.

The dynamic followed in all five groups was similar (all of them being conducted by a unique moderator), and corresponded to the five stages proposed by previous literature (Tuckman \& Jensen, 1977; Chrzanowska, 2002, pp. 52, cit in Catteral \& Maclaran, 2006). At the beginning of each focus group, the facilitator posed a relatively general question (see question A), and invited participants to share the examples from the personal experiences, encouraging interaction. In spite of how strong or weak the respondents' personality appeared to be, the facilitator included every member in the talk, preventing confrontation which would add no knowledge to the discussion, and facilitating 
clarifications and positive responses by the mostly possible methods of all times, so as to guarantee the most spontaneous responses.

\section{Results and Discussion}

\subsection{The Get-dimensions - Benefits}

According to discussions in all five focus groups, perceived image is one relevant value sought in HE consumption. Consequently, reputation directly associates with the universities' image. This result is clearly in accordance with previous literature, as image and reputation is stated as one of the institutional factors influencing University choice in Hemsley-Brown and Oplatka (2015)'s comprehensive model. In fact, while normally students would seek for word-of-mouth, they also testify the universities with the resources they possess. Regarding information sources, the participants of our research mentioned the three information sources identified by Bonnema and van der Weldt (2008): i.e. direct resources, media sources and social sources, but relying first in the direct and media ones, and secondly looking for positive recommendations. Results showed that the participants in the focus groups, as foreign students look at the ranking system for reference of the university image before their entry to the country where the made the Master program. In this sense, the publication of the ranking provides means for the prospective students the possibilities of which university they could afford to enter.

Experiences of image and reputation as a benefit perception driving their choice were provided in all focus groups. As aforementioned, except for one case, students in each focus group came from the same University (see Table 1); the homogeneity in finding University image as a driver is not surprising, according to previous literature (Hemsley-Brown \& Oplatka, 2015). As a matter of example, It was told in focus group A that the students viewed their institution as "one of the top ones among the others in Spain". One of the attended students mentioned that the information about the university should be received from different channels, such as "website, recommendations from former graduates or any of the known". Moreover, it was also mentioned as a relevant benefit found in their particular choice, the advantage provided by the program for the students from focus group $\mathrm{A}$, is that it gives the qualified students "two degree within one year" (FG B was conducted with students from an international MBA at Universidad de Valencia that offers double diplomas among 7 different Universities worldwide). 
Progressing among the positive values, it was generally agreed that good teachers is another benefit, because of knowledge they have accumulated as well as their precise offering abundant practical experiences. This result corresponds to previous findings from the literature, related to "outcomes and benefits of Higher Education, including social and lifestyle benefits of Higher Education participation" (Hemsley-Brown \& Oplatka, 2015, pp. 265). In our case, although our research is explorative and fully contextual, what is interesting is how these outcomes and benefits relate to the three dimensions of value: functional, social and emotional. In this sense, "a friendly and easy going relationship with instructors" (FG A) was seen as an emotional value. Meanwhile, the benefits from quality education also derived from teamwork with the colleagues who possess equal academic strength. While regardless of good or bad cooperation, it leads to positive outcomes as it helps to improve interpersonal skills by the cope-up of different working paces to with each other.

One additional benefit also mentioned, corresponding to social dimension of value, was the experiences outside the academic environment: in "working with people from different cultural backgrounds who have different perspectives" (FG D), which would equip the students the valuable capabilities to unite every team member in one. The Master degree will give the student an opportunity "to make differences in life" (FG C), since Higher Education improves their level of strength for practice and enables them "to be more confident for a decent job" (FG E). In this sense, it is perceived as a "mental gym to build up the fundamental basis for real world operations" (FG B). All these aspects correspond to aspects of lifelong learning in Higher Education, which are relevant also in previous works with international students such as Aydin (2012).

The course content is another major benefit sought, and consequently a key determinant in selecting the universities for the prospective students who search particular courses that fit in the personal interest. As one respondent mentioned (FG B), he chose the University of Valencia out of the others as it has "a program here which specializes in the field of marketing"; moreover, as it is an exchange program, the students would "gain experiences from the Spanish culture, which is significantly different from the North European ones (i.e. Germany, Austria, etc.”). Apparently, according to the discussion held by participants, emotional and social values are added to the functional one of the course content. Furthermore, depends on what the students would like to study as mentioned by the FG C, in certain circumstances, some subjects matter more than others (i.e. psychology, lawful courses, etc.). In specialized learning, students would pay attention to the syllabus.

"Higher education ensures a promising future for one's career life" (FG E); in many universities that provide the opportunity to work closely with the related industries and offer internship to the students 
during studying. These invaluable experiences would enable the students to "know the way of the rocks" (FG A), as the Mexican way of saying that "now you know the other side of the world". On the other hand, it builds up the students' confidence for entrepreneurship, to make something of their own in the foreseen future (as indicated by FG A and E members). However, a few pointed out that it was not solely the confidence that matters for a start-up of one's business, but rather depends on one's personality. "The Master students would be more capable to differentiate themselves from others in the marketplace" (FG D), and for this reason "the employers will give priority to their expertise in the recruitment". The students who would obtain a master degree shortly believed that they have some edge in the labour market.

According to affective values, one precise idea emerging from our results relates to the preference of one university over the others based on a certain "educational tourism". As also stated in the aforementioned research by Hemsley-Brown and Oplatka (2015), geography is a driver for University election, but it remains unclear, out of our results, if International Master students really look for proximity, or the geographical issue concerns more a search of diversity and novelty. Cultural distance has also underpinning in this evaluation, as some participants in Group A were Latin-American studying in Spain, a country geographically very distant, but culturally (language, religion) close. Meanwhile, the geographic location could be an attractive appeal to the students, as well as the environment of the city where they have never been before. For instance, in the course offered by the UV, students would study in one country for the first semester and move to another for the second in either Europe or America (i.e. UK, US, Spain, France, Germany). Thus students anticipated that in Valencia (FG A and B), they will be able to enjoy the events that frequently take place in a great weather and cites of attraction along the coastline. On the other hand, in accordance with what Aydin (2012) found for (undergraduate) Erasmus students, for the purpose to improve the language skills that a student would chose particular country without too much concern about the course content (FG D).

Location and cultural background are also very important in students' selection of the universities (FG A and B), but as mentioned earlier, more in the search of novelty than proximity. For instance, "students who come to the UK tend to place more importance to the country rather than the particular university" (FG D), as the social experiences are the most considered. In some cases, a Western degree seems to be a worthy investment and the key to the future (FG D and E), which shows how cultural issues are at a play in the Higher Education experience for international students. It is the acknowledgment of one's ability, which is positive for the build-up of students' confidence. As a result, the students gain the competitive advantage in the marketplace and are more likely to succeed in the 
pursuit of a better employment opportunity, which is a positive driver also mentioned in related works (e.g. Aydin, 2012; Hemsley-Brown \& Oplatka, 2015).

On the other hand, the family is usually the most powerful reference group for foreign students in their choice of universities, since they own the control of the finance, the trust of the students' and the preference of certain subjects they would like the students to study. In addition, "parents are generally proud of their children's achievements" (FG E). In this sense, a social value appeared in FG C and E: "relatives would naturally see us in a better light after we obtain a higher degree from a foreign country", as it is considered that the money was spent wisely. The value trade-off appeared in this sense: emotional reward for the price paid. In that sense, students from the Group E said that "if the family is reasonably supportive for the students, the latter would be more motivated in accomplishing the degree, and more likely to achieve better results"; whereas in an opposite situation, "the students from the indifferent family would feel disappointed or even frustrated in their study". However, there is no consensus within the five groups in this case. In this sense, there is a sharp cultural issue at a play in this social value added towards the esteem experienced by family and relatives in our work, which was clearer within the Chinese students (Group E), than in any other group.

\subsection{The Give-dimensions - Sacrifices}

At the other end of the spectrum, there are several aspects of concern in consideration of the monetary and non-monetary costs. Broadly speaking, the living expense was mentioned, as in other previous works reviewed by Hemsley-Brown and Oplatka (2015), but for the precise participants involved in our research, cost of living seem to be much more expensive in a metropolitan city "where the student can receive the best resources and facilities for higher education" (FG E). And once the living costs largely increase, it is perceived as a "significant challenge" for the students. In this way, according to our explorative findings, the student would choose a master course for which he/she think "the money will be genuinely worth of value (based on what is to be learnt; or to obtain the international experience if otherwise would not be available)" (FG B)

Non-monetary costs for the foreign students investigated are usually in terms of nostalgia ("being absent to the homeland (FG A), "feeling homesick" (FG B), "suffering from the cultural shock" (FG D). In some circumstances, the non-monetary costs become the non-academic benefits. For example, "the emotional sacrifice can turn into benefits" (FG B), as the students would need to learn how "to start over by their own", "to understand and communicate with the others", and "to clear off certain 
emotional hurdles in a totally new environment" rather than "a shelter protection of home" (FG A). In this case, it is precious life experience, for a student "to learn how to get along with people in the society when they go out for employment" (FG E); prior to that, it is the same in the university, they can pick their friends, they can't pick their classmates. It is a "grow-up process which takes the students to the final stage to the adulthood" (FG C).

For another, when the bursary or national subsidies and the master course are basically "tuition-free", the discussion turned into how students would consider other elements such as the "cultural diversity" or "prospective economic development of the city" into account (FG C). In the contrast, the students who view the tuition fee as an essential would "perceive the bursary or subsidy as the determinant to attend the master course" (FG A). Since these precise students are not usually economically independent and sponsored by their parents, it is a psychological burden if they had to pay. In this case, some would give up while the rest of them would consider 100\% worth it among the universities, taking the teaching quality, the potential network of alumni into consideration. However, the geographic location and the weather were not an issue in such situations, "as long as they are affordable/tolerable" (FG D).

Among non-monetary costs, the most commonly mentioned aspect is the "language barrier" (FG A, B and E). For instance, the foreign students whose mother tongue is not English would have to pass the IELTS test for studying in the UK, or the GMAT for the US and France. Likewise, the language barriers occur to a few students in an alien place "where there is a prevalent dialect (e.g. Cantonese in South China)" (FG E). Although some of these results are rather contextual, they correspond to what has been found in previous works selected by Hemsley-Brown and Oplatka (2015), and they suggest differences in student's value perceptions according to the cultural backgrounds.

Considering the sacrifice of time and other efforts, results show how "the time you could have spent with your family, could be made up by meeting new friends" (FG E). Moreover, for this precise sample of students, comparing with working people, there is "the freedom to go home in vacations as a student still" (FG E). Speaking from another (still non-monetary) dimension, the complicated procedures "financial conditions, applied course, other documents required for visa application" was deemed as a drawback from the program setting (FG A and B). In certain situations, there were limited alternatives in the choice of universities left to the students for reasons such as "late enrolment due to visa problems for the foreign coming students" (FG C). Moreover, due to the fear to have too many people overload the national labour market, or to take advantage of the public services in the recent years, unfair treatments to immigrants occur in the country border while the "officials double-checked 
the non-European passengers for prevention of terrorist attacks", as quoted from a student from FG $\mathrm{D}$, and also "the situations become more severe after the crisis" (FG B).

Meanwhile, unexpected age discrepancy of the colleagues appeared to one member that as a professional course, "you hope to share real life experiences, not only from the teachers" (FG D). Due to similar reasons, there is a tendency of depreciation and confusion that occurs in the view of the society, as "the supposedly higher academic experience dose not equal to practical ability" (FG B). "Comparing with the postgraduates, the choices for the undergraduate could be wider and more flexible" (FG C), since the MA students are more fixed in certain areas and professional oriented in the job hunting.

Regarding the last questions, whether all the positive and negative aspects of their experience are traded-off in their minds, it could be said that a relationship between consumer behaviour theory and the value trade-off clearly emerged from our empirical research: during the series of stages that followed by the customers who seek for the Higher Education services, while the gap between the assumed state and the actual situation at the phase classified as "problem recognition" (Moogan, 2001) appears, the students would decide whether to solve the disparity or not by balancing benefits with sacrifices: "Yes there is always a balance in our minds, when we decided to choose this course" (FG A).Accordingly, it could be said that a student in this case will consider whether taking the education will be worthwhile or beneficial in solving their existing problems, such as the enhancement of social abilities, professional skills or employment opportunities. Additionally, the second phase of "information search" (Moogan, 2001) occur, in which the prospective students would gather universities data as the reliance of purchase. Therefore, nearly all participants in the focus groups confirm the idea also found in outer works (e.g. Bonnema and van der Weldt, 2008) that in this stage, they may look for information either/both internally from their own impression or/and externally from the descriptions and recommendations of other sources.

\section{Conclusions}

In this research, it has been explored the consumption of HE services with the factors concerning international Master students' perception toward value as a trade-off between benefits and sacrifices. As Higher Education institutions now operate in a competitive environment, where choices are not stable but change over time, (Hemsley-Brown \& Oplatka, 2015), it is crucial to address the ideas of value perceived by the students as positive and negative dimensions of value. The technique chosen for this 
explorative aim has been focus groups, as "focus groups are a useful tool to expand existing knowledge about service provision and identify consumer needs ... particularly within multicultural populations" (Halcomb et al., 2007, pp. 1001).

According to the qualitative information collected and keeping in mind the relevance of cross-cultural understanding of the HE experience (Sulkowski \& Deakin, 2009), the results show different levels of benefits: the functional value generally comes from infrastructures and good teachers that offer abundant practical experiences. Meanwhile, the benefits from quality education also derived from teamwork with the colleagues who possess equal academic strength. Social benefits come mainly from experiences outside the academic environment, working with people from different cultural backgrounds who have different perspectives. Emotional rewards come from University reputation and relationships with instructors. Costs of time and effort are differently seen across programs and vary widely upon nationalities and cultural backgrounds.

Value is considered to be one of the core characteristics of a successful organization focuses on (Day, 1999; Holbrook, 1999). Since the competitive environments are fast becoming more and more complex added to the fact that it changes rapidly and dynamically, to concentrate on a few key elements are most important to the organizations survival. Different values of customers in different countries suggest that the strategy used by the corporation in a certain country, may not be apply to another.

The support or opposition from parents could be influential, but not decisive still, due to the fade idea or even ignorance of the knowledge about the courses chosen by the students. Besides, there is a need for the students to find place where they want to live and the city that corresponds to them. Social and affection needs such as friendship and personal network to be built, can provide the appeal of excitement to the students. Sometimes it would be a personal challenge as there is a lack of experience to survive in a foreign country/city, as in this case, the students need to adapt to a new environment. Nevertheless, the excitement is infinite in big cities while the only difference is in the culture.

In specific, this paper has made an attempt to gain an explorative understanding in the postgraduate students' experience of education during their Masters' degrees and explore the consumer behaviour of students in the particular market when choosing and consuming the Higher Education service. Regarding previous works, the contribution made by this study relates to three aspects:

- the public chosen, international Master students, who have been more scarcely researched (Hemsley-Brown \& Oplatka, 2015, pp. 268); 
- the value-based approach, where behavioural dimensions of different nature have been explored (social, functional and emotional),

- the consideration of monetary and non-monetary costs as an enlargement of previous models such as Hemsley-Brown and Oplatka (2015)'s one.

In general, our explorative findings show that when the students are conscious about the significance of the financial sacrifice for a Higher Education degree, they would balance the cost against the possible outcome, try not to be the burden of their family and achieve better learning quality by genuine efforts. Our results in this sense confirm and enhance previous works (Hemsley-Brown \& Oplatka, 2015; Reay et al., 2001; Bamber, 2014), in the sense that the educational market is not homogeneous, and each experience is fully contextual, and in some sense unique. This is again a reason for considering qualitative techniques in educational research, where inner feelings and motivations can be better appraised, and therefore help HEIs in finding the best marketing tools, closer to micro-segmentation that to mass communication, for achieving students' satisfaction and positive word-of-mouth. In this sense, managers in HEIs should be aware of the dual nature of the educational experience, where not only functional utilities (facilities, spaces, exchange programs...) and at a play, but also the emotional and social aspects: favouring mentoring programs for new students, social activities in Facebook, Twitter or University platforms, and obviously alumni's programs can reinforce these aspects, and produce significant improvements in positive word-of-mouth.

Nevertheless, we also know that the choice of HEIs is as well influenced by a set of multivariate characteristics. Internally, it occurs the socio-economic state, aptitude, education level and capabilities of high school which possessed by the students; meanwhile, there are the external elements such as the impact of great person, the institution's ability to communicate with the potential students and other fixed factors within certain environments. The complex idiosyncrasy of education consumption demands comprehensive approaches, such as the value-based one, where a positive trade-off between benefits and costs in education will lead to satisfied and loyal (educational) consumers.

Consequently, given that values are critical factors for developing trust and commitment, for the precise public of international students, our research findings can help in supporting that national culture affects the different values perceived in the HE experience. In this sense, this study points out in the direction of the goodness of primary investigation and allocation of Higher Education resources in the global market. 
At the end of this study, several limitations ought to be acknowledged, leading to future research options. First, the choice of the countries (UK, China and Spain) is unbalanced (three among five focus groups took place in in Spain) and discretionary. Although the three countries are relevant for an international approach to HEIs, the results and outcomes derived from the focus groups are contextspecific. Furthermore, in one focus group, all students came from the same country (China), although from very distant geographical areas; this may have damage the heterogeneity of the discussion in this group, in comparison to others. Second, although the participants had different origins, the multicultural scope of the results that have surfaced our discussion could have been better apprehended through a model (Hofstede or other): combination with quantitative techniques in the exploration of the tenets and expressions made through precise software for qualitative analyses can throw a new light in these intercultural aspects of the international students' value perceptions.

Third, the value based approach adopted in this paper could be enlarged with the inclusion of value perceptions of other stakeholders relevant in the HE service provision (teachers and/or managers). In this sense, the trade-off approach could be envisioned though the lens of a value co-creation process (Grönroos \& Voima, 2013), where both service providers and consumers are relevant actors. Recent works have already advocated for this approach (e.g. Mark, 2013, pp. 8); in our view, qualitative methods, and more precisely focus groups, could bring substantial knowledge through in group discussions on the education experience for different key players.

\section{References}

Angulo, F., Pergelova, A., \& Rialp. J. (2010). A market segmentation approach for higher education based on rational and emotional factors. Journal of Marketing for Higher Education, 20(1), 1-17. http://dx.doi.org/10.1080/08841241003788029

Arambewela, R., Hall, J, \& Zuhair, S. (2005). Postgraduate International Students from Asia: Factors Influencing Satisfaction. Journal of Marketing for Higher Education, 15(2), 105-127. http://dx.doi.org/10.1300/J050v15n02_05

Aydin, S. (2012). I Am Not the Same after My ERASMUS: A Qualitative Research. Qualitative Report, 17(55), 1-23.

Bamber, M. (2014). What motivates Chinese women to study in the UK and how do they perceive their experience?. Higher Education, 68, 47-6. http://dx.doi.org/10.1007/s10734-013-9679-8 
Bitew, G. (2016). A qualitative study of the academic and social factors affecting latino students at a liberal arts college: Accomplishments and challenges. International Journal of Educational Research, 75, 57-66. http://dx.doi.org/10.1016/j.ijer.2015.11.007

Boksberger, P.E., \& Melsen. L. (2011). Perceived value: A critical examination of definitions, concepts nad measures for the service industry. Journal of Services Marketing, 35(3), 229-240. http://dx.doi.org/10.1108/08876041111129209

Bolton, R.N., Kannan, P.K., \& Bramlett, M.D. (2000). Implications of loyalty program membership and service experiences for customer retention and value. Journal of the Academy of Marketing Science, 28(1), 95-108. http://dx.doi.org/10.1177/0092070300281009

Bonnema, J., \& van der Weldt, D.L.R. (2008). Information and source preferences of a student market in higher education. International Journal of Educational Management, 22(4), 314-327. http://dx.doi.org/10.1108/09513540810875653

Breen, R.L. (2006). A practical guide to focus group research. Journal of Geography in Higher Education, 30(3), 463-475. http://dx.doi.org/10.1080/03098260600927575

Catterall, M., \& Maclaran, P. (2006). Focus groups in marketing research. In Handbook of Qualitative Research Methods in Marketing, (Chapter 19, pp. 255-267). http://dx.doi.org/10.4337/9781847204127.00027

Chrzanowska, J. (2002). Interviewing groups and individuals in qualitative market research (Vol. 2). Sage.

Day, G.S. (1999). Market driven strategy. Processes for creating value (2nd ed.). New York: The Free Press.

Deshields Jr., O.W., Kara, A., \& Kaynak, E. (2005). Determinants of business student satisfaction and retention in higher education: Applying Herzberg's two-factor theory. International Journal of Educational Management, 19(2), 128-139. http://dx.doi.org/10.1108/09513540510582426

Dodds, W.B., \& Monroe, K.B. (1985). The Effect of Brand and Price Information on Subjective Product Evaluations. In E.C. Hirschman \& M.B. Holbrook (Eds.), Advances in Consumer Research (pp. 85-90). Association for Consumer Research.

Eagle, L., \& Brennan, R. (2007). Are students customers? TQM and marketing perspectives. Quality Assurance in Education, 15(1), 44-60. http://dx.doi.org/10.1108/09684880710723025

Finch, H., \& Lewis, J. (2003). Focus groups. Qualitative research practice: A guide for social science students and researchers (170-198).

Fombona, J., Rodríguez, C., \& Sevillano, M.Á.P. (2013). The Motivational Factor of Erasmus Students at the University. International Education Studies, 6(4), 1-9. http://dx.doi.org/10.5539/ies.v6n4p1 
Gallarza, M.G., Gil-Saura, I., \& Holbrook, M.B. (2011). The value of value: Further excursions on the meaning and role of customer value. Journal of Consumer Behaviour, 10(4), 179-191. http://dx.doi.org/10.1002/cb.328

Grönroos, C., \& Voima, P. (2013). Critical service logic: Making sense of value creation and cocreation. Journal of the Academy of Marketing Science, 41(2), 133-150. http://dx.doi.org/10.1007/s11747-012$0308-3$

Gummerus, J. (2013). Value creation processes and value outcomes in marketing theory: Strangers or siblings?. Marketing Theory, 13(1), 19-46. http://dx.doi.org/10.1177/1470593112467267

Halcomb, E.J., Gholizadeh, L., Digiacomo, M., Phillips, \& Davidson, P.M. (2007). Literature review: Considerations in undertaking focus group research with culturally and linguistically diverse groups. Journal of Clinical Nursing, 16, 1000-1011. http://dx.doi.org/10.1111/j.1365-2702.2006.01760.x

Hemsley-Brown, J.A., \& Oplatka, I.B. (2015). University choice: What do we know, what don't we know and what do we still need to find out?. International Journal of Educational Management, 29(3), 254-274. http://dx.doi.org/10.1108/ijem-10-2013-0150

Holbrook, M.B. (1999). Consumer value. A framework for analysis and research. London: Routledge. http://dx.doi.org/10.4324/9780203010679

Holbrook, M.B., \& Hirschman, E.C. (1982). The experiential aspects of consumption: Consumer fantasies, feelings, and fun. Journal of Consumer Research, 9, 132-140. http://dx.doi.org/10.1086/208906

Jensen, H.R. (1996). The interrelationship between customer and consumer value. Asia Pacific Advances in Consumer Research, 2, 60-63.

Jensen, R.E., Christy, K., Gettings, P.E., \& Lareau, L. (2013). Document Interview and Focus Group Research: A Content Analysis of Scholarship Published in Ranked Journals. Communication Methods and Measures, 7(2), 126-133. http://dx.doi.org/10.1080/19312458.2013.789838

Jowett, M., \& O'Toole, G. (2006). Focusing researchers' minds: Contrasting experiences of using focus groups in feminist. Qualitative Research, 6(4), 453-472. http://dx.doi.org/10.1177/1468794106068014

Kress, V.E., \& Shoffner, M.F. (2007). Focus groups: A practical and applied research approach for counselors. Journal of Counseling and Development: JCD, 85(2), 189. http://dx.doi.org/10.1002/j.15566678.2007.tb00462.x

Lai, A.W. (1995). Consumer values, products benefits, and customer value: A consumption behavior approach. Advances in Consumer Research, 22, 381-388. 
Ledden L., Kalafatis, S.P., \& Samouel, P. (2007). The Relationship between Personal Values and Perceived Value of Education. Journal of Business Research, 60, 965-974. http://dx.doi.org/10.1016/j.jbusres.2007.01.021

Lee, H.-J., Lee, J., Makara, K.A., Fishman, B.J., \& Hong, Y-I. (2015). Does higher education foster critical and creative learners? An exploration of two universities in South Korea and the USA. Higher Education Research \& Development, 34(1), 131-146. http://dx.doi.org/10.1080/07294360.2014.892477

Lehmann, D., Mcalister, L., \& Staelin, R. (2011). Sophistication in Research in Marketing. Journal of Marketing, 75(4), 155-165. http://dx.doi.org/10.1509/jmkg.75.4.155

Leroi-Werelds, S., Streukens, S., Brady, M.K., \& Swinnen, G. (2014). Assessing the value of commonly used methods for measuring customer value: A multi-setting empirical study. Journal of the Academy of Marketing Science, 42(4), 430-451. http://dx.doi.org/10.1007/s11747-013-0363-4

Levy, D. (2006). Qualitative methodology and grounded theory in property research. Pacific Rim Property Research Journal, 12(4), 369-388. http://dx.doi.org/10.1080/14445921.2006.11104216

Lovelock, C.H. (1983). Classifying Services to Gain Strategic Marketing Insights. Journal of Marketing, 47(3), 9-20. http://dx.doi.org/10.2307/1251193

Lovelock, C.H. (1996). Services Marketing (3rd ed.). Englewood Cliffs, NJ: Prentice-Hall.

Malhotra, N.K. (2010). Marketing research: An applied orientation (Vol. 834). New Jersey: Pearson Education. http://dx.doi.org/10.1108/S1548-6435(2010)6

Marín-García, J.A., Martínez-Gómez, M., \& Giraldo-O’meara, M. (2014). Rediseñando el trabajo en las aulas universitarias: Factores relacionados con la satisfacción en estudiantes de ingeniería y administración de empresas. Intangible Capital, 10(5), 1026-1051.

Mark, E. (2013) Student satisfaction and the customer focus in higher education. Journal of Higher Education Policy and Management, 35(1), 2-10. http://dx.doi.org/10.1080/1360080X.2012.727703

Moogan, Y.J. (2001). Timings and trade-offs in the marketing of higher education courses: A conjoint approach. In Marketing Intelligence \& Planning (179-187). MCB University Press. http://dx.doi.org/10.1108/02634500110391726

Nilson, T.H. (1992). Value-added marketing: marketing management for superior results. Berkshire, UK: McGraw Hill.

Oliver, R.L. (1999). Whence consumer loyalty?. Journal of Marketingi, 63, 33-44. http://dx.doi.org/10.2307/1252099 
Parasuraman, A., \& Grewal, D. (2000). The impact of technology on the quality-value-loyalty chain: A research agenda. Journal of the Academy of Marketing Science, 28(1), 168-174. http://dx.doi.org/10.1177/0092070300281015

Patton, M.Q. (2002). Qualitative research and evaluation methods. Thousand Oaks: Sage.

Reay, D., Davies, J., David, M., \& Ball, S.J. (2001). Choices of degree or degrees of choice? Class, ‘race` and the higher education choice process. Sociology, 35(4), 855-874.

Ritchie, J., Lewis, J., \& Elam, G. (2003). Designing and selecting samples. Qualitative research practice: A guide for social science students and researchers, 2, 111-145.

Sulkowski, N.B., \& Deakin, M.K. (2009). Does Understanding Culture Help Enhance Students' Learning Experience?. International Journal of Contemporary Hospitality Management, 21(2), 154-166. http://dx.doi.org/10.1108/09596110910935651

Sweeney, J.C., Soutar, G.N., \& Johnson, L.W. (1999). The role of perceived risk in the quality-value relationship: A study in a retail environment. Journal of Retailing, 75(1), 77-105. http://dx.doi.org/10.1016/S0022-4359(99)80005-0

Tuckman, B.W., \& Jensen, M.A.C. (1977). Stages of small-group development revisited. Group \& Organization Management, 2(4), 419-427. http://dx.doi.org/10.1177/105960117700200404

Vargo, S.L., \& Lusch, R.F. (2012).The nature and understanding of value: A service-dominant logic perspective. In S.L. Vargo \& R.F. Lusch (Ed.). Toward a Better Understanding of the Role of Value in Markets and Marketing (Review of Marketing Research) (9: 1-12 ). Bingley, UK: Emerald. http://dx.doi.org/10.1108/s1548-6435(2012)0000009005

Verghese, A., \& Kamalanabhan, T.J. (2015). Attributes influencing information search for College choice: An exploratory study. Int. J. Business Innovation and Research, 9(1), 34-51. http://dx.doi.org/10.1504/IJBIR.2015.065952

Watt, C., Angelis, J., \& Chapman, D. (2012). Customer value and lean operations in masters education. Proceedings of the 14th International Conference on Engineering and Product Design Education: Design Education for Future Wellbeing, EPDE 2012, pp. 699-704.

Winlow, H., Simm, D., Marvell, A., \& Schaaf, R. (2013). Using Focus Group Research to Support Teaching and Learning. Journal of Geography in Higher Education, 37(2), 292-303. http://dx.doi.org/10.1080/03098265.2012.696595 
Woodruff, R.B. (1997). Customer value: The next source for competitive advantage. Journal of the Academy of Marketing Science, 25(2),139-153. http://dx.doi.org/10.1007/BF02894350

Woodruff, R.B., \& Gardial, S. (1996). Know your customer: New approaches to customer value and satisfaction. Cambridge, Mass., USA: Blackwell Business,

Zeithaml, V.A. (1988). Consumer Perceptions of Price, Quality, and Value: A Means-end Model and Synthesis of Evidence. Journal of Marketing, 52(3), 2-22. http://dx.doi.org/10.2307/1251446

Zeithaml, V.A., \& Bitner, M.J. (1996). Services Marketing. McGraw-Hill.

Intangible Capital, 2016 (www.intangiblecapital.org)

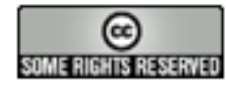

Article's contents are provided on an Attribution-Non Commercial 3.0 Creative commons license. Readers are allowed to copy, distribute and communicate article's contents, provided the author's and Intangible Capital's names are included. It must not be used for commercial purposes. To see the complete license contents, please visit http://creativecommons.org/licenses/by-nc/3.0/. 